Research Article

\title{
Albumin impact on clinical practice and complications of ischemic stroke in patients with stroke
}

\author{
Vahid Abbasi, Ghasem Fattahzadeh-Ardalani*, Pooneh Safarnejad, Roghayeh Aslanian
}

Department of Neurology, Ardabil University of Medical Science, Ardabil, Iran

Received: 11 June 2016 Accepted: 12 August 2016

*Correspondence to: Dr. Ghasem FattahzadehArdalani,

Email: G.fattahzadeh2015@ gmail.com

Copyright: (C) the author(s), publisher and licensee Medip Academy. This is an openaccess article distributed under the terms of the Creative Commons Attribution NonCommercial License, which permits unrestricted noncommercial use, distribution, and reproduction in any medium, provided the original work is properly cited.

\begin{abstract}
Background: Cerebrovascular disease is the third common leading cause of death after cancer and heart disease in the United States. Also cerebrovascular disease is the most common neurological disease which can lead to complications or mortality. The incidence of ischemic stroke increases with age, and almost two thirds of cases occur in people over 65 years. Albumin as a blood thinner to reduce blood viscosity and sufficient vasodilation in response to low oxygen increases blood flow in ischemic and normal brain. The aim of this study was to investigate the Albumin impact on clinical practice and complications of ischemic stroke in patients with stroke.
\end{abstract}

Methods: This is a randomized clinical study that has been done on 100 patients with ischemic stroke included 54 male and 46 female referred to Alavi hospital in Ardabil. Patients with inclusion criteria randomly divided in two similar sample size groups. For case group we prescribed albumin $20 \%$ and for control group normal-saline. NIHSS questionnaire completed for each patient based on their interview and medical documents in hospital according the specialist doctor idea. Collected data analysed by statistical methods in SPSS.19.

Results: From all patients, $41 \%$ have HTN, 30\% Diabetes, 32\% ischemic stroke type cortical in branch MCA and $14 \%$ in brain stem. The highest risk factor for stroke was in people with high blood pressure. The mean of NIHSS in the end of third month after intervention in the patients with cortical ischemia in albumin group with $24.8 \pm 5.1$ was lower than placebo group with $31.3 \pm 3$ and this difference was statistically significant $(\mathrm{p}=0.012)$.

Conclusions: Results showed that in cortical ischemic stroke there was a significant relationship between receiving albumin and decreasing NISHH score. But there was no significant relationship between receiving albumin and decreasing NISHH score in Lacunar and brain stem stroke.

Keywords: Ischemic stroke, Albumin, Ardabil

\section{INTRODUCTION}

Stroke is the third leading cause of mortality in developed countries after coronary heart disease and cancer. ${ }^{1}$ It was estimated that the incidence of stroke is predicted to increase over the next $5-10$ years by $12 \%$ in the general population and by $20 \%$ in low-income subjects. ${ }^{2}$ Mortality rates during the first 30 days after stroke and at 1 year are $20 \%$ and $30 \%$, respectively. The large majority $(65-85 \%)$ of strokes in the Western world are ischemic whereas haemorrhagic strokes, which are less frequent, are more disabling. ${ }^{3}$
Stroke remain as a common issue in the health system and is one of three causes of death in many countries and a large part of neurological damage associated with stroke, which would impose enormous costs to the health system. ${ }^{4}$

Stroke is a syndrome of acute neurologic symptoms for at least 24 hours to be determined. Acute onset and duration of symptoms is determined based on the patient's history and a neurological examination which confirmed by CTScan and MRI. ${ }^{5}$

Stroke causes to symptoms and type of them related to one area of brain which feeding by vessels. In cerebral 
ischemia, the occlusion cause to cut off blood flow in a specified area of the brain and disorder due to the neurological actions in this area cause to incidence of similar symptoms. ${ }^{6}$

Cut off blood flow, deal to exclusion of neurons and other cells from glucose and oxygen and in the non-rapid establishment of blood flow deal to cell death and type of it related to ischemic severity. Many factors such as HTN, more Alcohol consumption, uses contraceptive drugs and genetic have main role in incidence of stroke.

Stroke is also the result of numerous mendelian disorder that mainly affects the heart and blood vessels, such as cardiomyopathy and arrhythmias family, homocystinuria, dyslipidemia, hemoglobinopathy, coagulopathy and connective tissue disorders and migraines. In addition, there is a variety of monogenic syndrome, in which the main manifestation is stroke but the causes of more strokes probably multi-factorial included environmental and multi-genetic factors. ${ }^{5}$

Early diagnosis and true management of stroke is important in prognosis of patients.

Many efforts have been done about the decreasing of mortality in patients with ischemic stroke which one of them is the effect of neuroprotective agents in stroked patients. ${ }^{3}$

Neuroprotective drugs had been prescribed some hour after ischemia and could be decrease the volume of infarcts. $^{7}$

Based on recent studies it seem that albumin cause to recovery rate in prognosis of patients with ischemia. Tabernero and et al in a study showed that in pathological condition, albumin enter brain cells and may help maintain neuronal metabolism by increasing mechanisms. ${ }^{8}$

Belayev and et al in a study showed that treatment with moderate dose of albumin cause to recovery in neurologic condition, decreasing infarct volume and brain edema. ${ }^{9}$

Albumin is a protein soluble in water and one of the most important proteins in the plasma, which accounts for 65$55 \%$ of total protein in the body. Albumin is made in the liver and decrease in the liver, kidney, malnutrition and diabetes. The main function of albumin is tuning blood colloid osmotic pressure and its amount related to production, destruction, nutrition, blood oncotic pressure, liver disease, kidney disease and other chronic diseases. The use of albumin is considered as an independent risk factor for mortality in the elderly. There wasn't similar study in Iran on the role of albumin in stroke and because of the ischemic stroke is the most common mortality causes and its side effects deal to burden disease in society, so doing study on drugs and methods which can improve the prognosis of stroke and less disability of disease is important. The aim of this study was to investigate the albumin impact on clinical practice and complications of ischemic stroke in patients with stroke.

\section{METHODS}

This is a randomized clinical trial study that has been done on 100 stroked patients referred to Alavi hospital in Ardabil. Patients randomly divided in two groups each with 50 patients. One group receive albumin $20 \%$ with doses $2 \mathrm{gr} / \mathrm{kg}$ body weight for one week and other group take normal saline similar to first group. Two groups followed by three months. The inclusion criteria were age $>18$, low time of start clinical signs $(<12$ hour) and exclusion criteria were patients have kidney disease with creatinine more than 2.5 , pregnant patients, haemorrhagic stroke, SBP $>220 \mathrm{Mm} \mathrm{Hg}$ and DBP $<90 \mathrm{Mm} \mathrm{Hg}$, distress, heart block, advanced systemic disease, brain tumor, abscess and.

NIHSS questionnaire completed for each patient based on their interview and medical documents in hospital according the specialist doctor ideas. In NIHSS questionnaire the level of consciousness were, staring at the lesion ability to move in the opposite hemisphere, the field of vision, facial paresis, arm movement assessment (the paralysis), leg movements (the paralysis), sensory impairment assessments, ability to speak, ataxia and Extinction and neglect (excitation of each half on one side of the body just found stimulation) was assessed based on the severity of the stroke and the score from 0 to 42 detected for each item. In patients without symptoms of stroke the zero score and to patients with severe stroke score 21-42 score was rated. Collected data analysed by statistical methods in SPSS. $^{19}$

\section{RESULTS}

Of all patients, $46 \%$ were female with mean age $72 \pm 12.3$ (40-89). $41 \%$ of all patients have HTN which the upper risk factor is in this group. Among patients, the most type of ischemia was cortical in MCA area (32\%) (Figure 1).

From all patients with cortical stroke, 20 (43.5\%) were in case and other in control group. All patients followed in $24,48,144$ hour after beginning symptoms and also in three months based on NIHSS score and results showed that after 1-3 days before intervention, there wasn't significant relation between albumin and NIHSS decreasing rate but in the first, second and third month after intervention the difference was statistically significant (Table 1).

Also results in other patients with stroke in brain stem and lacunar showed that there wasn't any significant relation between albumin and NIHSS decreasing score. Of all ischemia, ischemia in brain stem have upper and lacunar have lower mortality rate (Figure 2). 


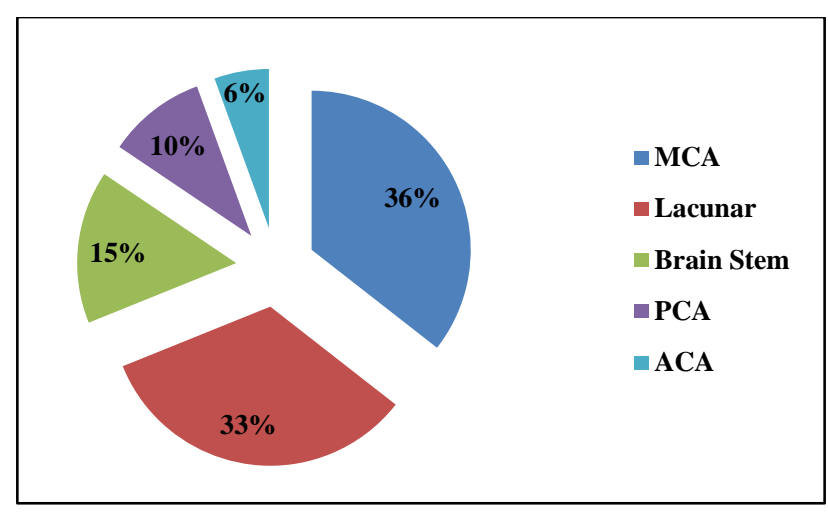

Figure 1: Type of ischemia in all patients.

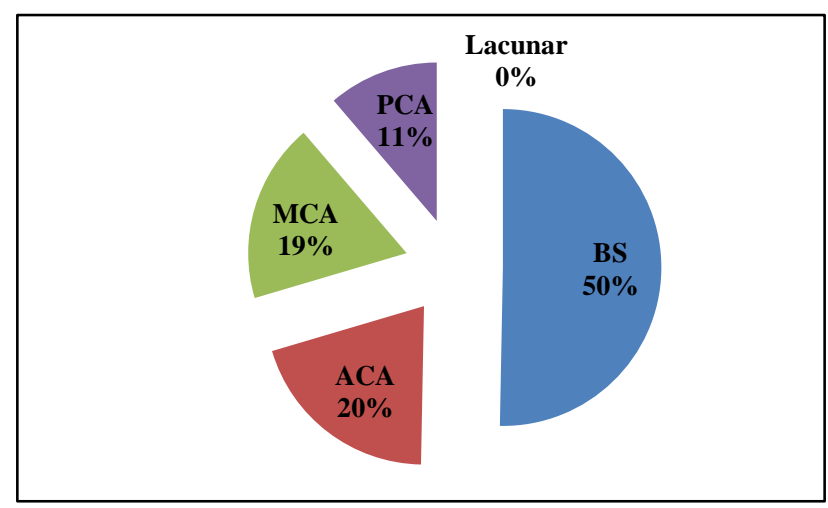

Figure 2: Mortality rate by ischemia type in all patients.

Table 1: Compare the mean score of NIHSS in patients with cortical ischemia.

\begin{tabular}{|c|c|c|c|}
\hline Time & Group & Mean \pm SD & p-value \\
\hline \multirow{2}{*}{$\begin{array}{l}\text { One month } \\
\text { late }\end{array}$} & Albumin & $28.2 \pm 0.5$ & \multirow{2}{*}{0.029} \\
\hline & Normal saline & $30.9 \pm 5.6$ & \\
\hline \multirow{2}{*}{$\begin{array}{l}\text { Two } \\
\text { month late }\end{array}$} & Albumin & $26.1 \pm 4.94$ & \multirow{2}{*}{0.025} \\
\hline & Normal saline & $30.9 \pm 3.92$ & \\
\hline \multirow{2}{*}{$\begin{array}{l}\text { Three } \\
\text { month late }\end{array}$} & Albumin & $24.8 \pm 5.1$ & \multirow{2}{*}{0.012} \\
\hline & Normal saline & $31.3 \pm 3$ & \\
\hline
\end{tabular}

\section{DISCUSSION}

Previous studies about relation albumin with clinical signs showed that clinical rate of serum albumin in acute ischemic stroke decrease the bad prognosis of disease.

In this study the result obtained that the effect of Albumin compare to the normal saline in stroke type cortical is effective. Didze and et al in a study by measurement the Albumin serum showed that hypoalbuminemia associated with mortality and morbidity increasing in patients. ${ }^{10}$

Famkin and et al in a study showed that Hypoalbuminemia is an independent risk factor predictor of mortality from ischemic stroke. ${ }^{11}$
This study showed that there wasn't any significant relation between mortality from stoke and using albumin. Babu MS and et al in a study showed that higher rate of serum albumin in ischemia stroke decrease from bad prognosis of disease. ${ }^{12}$

According to the Chkaraborty and et al study rate of albumin has significant relation with increasing severity of disease and long bad prognosis of diseases. ${ }^{13}$

Yuko and et al showed that higher doses of albumin therapy may have neuroprotective effects on ischemic stroke. ${ }^{14}$

Various study showed that Neuroprotective effects of Albumin significantly decrease if more than 4-5 hours after beginning stroke symptoms is past. ${ }^{15,16}$ Experimental studies showed that albumin therapy in moderate to high doses $(0.63-2.5 \mathrm{~g} / \mathrm{kg})$ in distance 2-4 hour after beginning stroke signs has major impact on reduce the size of infarction, cerebral edema and improvement of neurological symptoms. ${ }^{17}$

This study showed that albumin is effective on cortical stoke because serum albumin has multilevel microvascular effects and not only reduces the haematocrit, but also reduces the accumulation of erythrocytes and albumin is also an important antioxidant action against the oxidizing agents. ${ }^{9,18,19}$

Dziedzic $\mathrm{T}$ and et al in a study showed that higher level of albumin in stroke patients decrease risk of poor outcome. $^{20}$

\section{CONCLUSION}

Results showed that in ischemic stroke type cortical, there was a significant relationship between receiving albumin and decreasing NISHH score. But this relation wasn't significant other types of stroke such as Lacunar and brain stem. We can result that albumin has an impact on clinical practice and complications of ischemic stroke type cortical in patients with ischemic stroke.

Funding: No funding sources

Conflict of interest: None declared

Ethical approval: The study was approved by the Institutional Ethics Committee

\section{REFERENCES}

1. Scherbakov N, Doehner W. Sarcopenia in strokefacts and numbers on muscle loss accounting for disability after stroke. J Cachexia Sarcopenia Muscle. 2011;2(1):5-8.

2. Green AR. Pharmacological approaches to acute ischaemic stroke: reperfusion certainly, neuroprotection possibly. $\mathrm{Br} \mathrm{J}$ Pharmacol. 2008;153(Suppl 1):S325-338. 
3. Woodruff TM, Thundyil J, Tang SC, Sobey CG, Taylor SM, Arumugam TV. Pathophysiology, treatment, and animal and cellular models of human ischemic stroke. Mol Neurodegener. 2011;6:11.

4. Mitchell RS, Kumar V, Abbas AK, Fausto N. Robbins Basic Pathology, $8^{\text {th }}$ edn. Philadelphia, PA: Saunders; 2007.

5. Remmers M, Schmidt-Kastner R, Belayev L, Lin B, Busto R, Ginsberg MD. Protein extravasation and cellular uptake after high-dose human-albumin treatment of transient focal cerebral ischemia in rats. Brain Research. 1999;827(1-2):237-42.

6. Wolf PA, Abbott RD, Kannel WB. Atrial fibrillation: a major contributor to stroke in the elderly: the Framingham study. Arch Intern Med. 1987;147(9):1561-4.

7. Nadal A, Fuentes E, Pastor J, McNaughton PA. Plasma albumin is a potent trigger of calcium signals and DNA synthesis in astrocytes. Proc Natl Acad Sci USA. 1995;92(5):1426-30.

8. Tabernero A, Medina A, Sánchez-Abarca LI, Lavado E, Medina JM. The effect of albumin on astrocyte energy metabolism is not brought about through the control of cytosolic $\mathrm{Ca} 2+$ concentrations but by freefatty acid sequestration. Glia. 1999;25(1):1-9.

9. Belayev L, Zhao W, Pattany PM, Weaver RG, Huh PW, Lin B, et al. Diffusion-weighted magnetic resonance imaging confirms marked neuroprotective efficacy of albumin therapy in focal cerebral ischemia. Stroke. 1998;29:2587-99.

10. Dziedzic T, Slowik A, Szczudlik A. Serum albumin level as a predictor of ischemic stroke outcome. Stroke. 2004;35(6):e156-158.

11. Famakin B, Weiss P, Hertzberg V, McClellan W, Presley R, Krompf K, et al. Hypoalbuminemia predicts acute stroke mortality: paul coverdell georgia stroke registry. Journal of Stroke and Cerebrovascular Diseases. 2010;19(1):17-22.
12. Babu MS, Kaul S, Dadheech S, Rajeshwar K, Jyothy A, Munshi A. Serum albumin levels in ischemic stroke and its subtypes: correlation with clinical outcome. Nutrition. 2013;29(6):872-5.

13. Chakraborty B, Vishnoi G, Goswami B, Gowda SH, Chowdhury D, Agarwal S. Lipoprotein(a), ferritin, and albumin in acute phase reaction predicts severity and mortality of acute ischemic stroke in North Indian Patients. Journal of Stroke and Cerebrovascular Diseases. 2013;22(7):e159-167.

14. Palesch YY, Hill MD, Ryckborst KJ, Tamariz D, Ginsberg MD. The ALIAS pilot trial: a doseescalation and safety study of albumin therapy for acute ischemic stroke-II: neurologic outcome and efficacy analysis. Stroke. 2006;37:2107-14.

15. Belayev L, Lio Y, Zhao W, Busto R, Ginsberg MD. Human albumin therapy of acute ischemic stroke marked neuroprotective efficacy at moderate doses and with a broad therapeutic window. Stroke. 2001;32:553-60.

16. Tang J, Mu J, Li Q, Yang DY, Xie P. Albumin ameliorates tissue plasminogen activator-mediated blood-brain barrier permeability and ischemic injury in rats. Neurol Res. 2009;31(2):189-94.

17. Schnitzer J. Antibodies to SPARC inhibit albumin binding to SPARC, gp60, and microvascular endothelium. American journal of physiology. 1992;263(6 Pt 2):H1872-1879.

18. Reinhart WH, Nagy C. Albumin affects erythrocyte aggregation and sedimentation. European Journal of Clinical Investigation. 1995;25(7):523-8.

19. Zoellner H, Beckmann R, Beckmann R, Hufnagl P, Vanyek E, Bielek E, et al. Serum albumin is a specific inhibitor of apoptosis in human endothelial cells. J Cell Sci. 1996;109(Pt 10):2571-80.

20. Dziedzic T, Slowik A, Gryz-Kurek EA, Szczudlik A. Hypoalbuminemia in acute ischemic stroke patients: frequency and correlates. European Journal of Clinical Nutrition. 2007;61:1318-22.

Cite this article as: Abbasi V, Fattahzadeh-

Ardalani G, Safarnejad P, Aslanian R. Albumin impact on clinical practice and complications of ischemic stroke in patients with stroke. Int $\mathrm{J}$ Basic Clin Pharmacol 2016;5:2114-7. 